\title{
Effect Relationships bewteen Saety Conciousness, Safety Culture Design, Organizational Trust
}

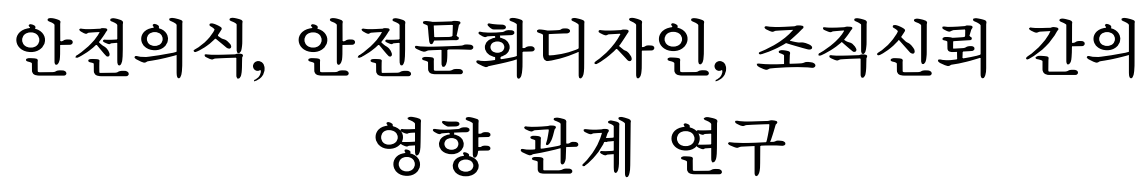

Kuk Hoan Wee ${ }^{1}$, Won Seok Bang ${ }^{2}$, So Eun Jang ${ }^{3}$, Seong Rok Chang ${ }^{4}$, Joung Hyung Cho ${ }^{5}$

위국환 ${ }^{,}$방원석 ${ }^{2}$, 장소은 ${ }^{3}$, 장성록 4 , 조정형 5

${ }^{1}$ Professor, GSIS Department, Pusan National University, Korea, wkh64@pusan.ac.kr

${ }^{2}$ Professor, Business Administration Department, Gyeongsang National University, Korea, bnagws@gnu.ac.kr

3 Professor, Education Department, Kyungsung University, Korea, naturejse@ks.ac.kr

${ }^{4}$ Professor, Safety Engineering Department, Pukyong National University, Korea, srchang@pknu.ac.kr

${ }^{5}$ Professor, Industrial Design Department, Pukyong National University, Korea, jhcho@pknu.ac.kr

Corresponding author: Joung Hyung Cho

\begin{abstract}
Industrial accidents that occur continuously are causing economic and social costs, and human casualties." These accidents remind us once again of the importance of safety consciousness and safety culture. To this end, this paper aims to investigate the relationship between safety rules, safety education, risk handling methods, which are elements of safety awareness design, safety culture design, and organizational trust. For this study, questionnaires were distributed to employees working in aviation-related manufacturing companies located in Gyeongsangnam-do. Among the 270 questionnaires collected, 254 questionnaires were used for analysis excluding those with invalid responses. Analysis was performed using the statistical programs SPSS 21.0 and AMOS 21.0. As a result of the study, first, it was confirmed that safety rules has a significant positive effect on safety culture design. Second, safety education had a significant positive effect on safety culture design. Third, it was confirmed that the risk handing method had a significant positive effect on the safety culture design. Fourth, safety culture design positively influenced organizational trust. Based on these research results, theoretical and practical implications are presented.
\end{abstract}

Keywords: Organizational Trust, Safety Consciousness Design, Safety Culture Design, Safety Education, Safety Rules

요약: 지속적으로 발생하고 있는 산업재해로 경제적, 사회적 비용 및 인명사고 등을 초래하고 있다. 이러한 사고는 안전의식, 안전문화에 대한 중요성을 다시 한번 일깨운다. 이와 같은 맥 락에서, 본 논문은 안전의식디자인의 요소인 안전규칙, 안전교육, 위험처리방식, 안전문화디자 인, 조직신뢰 간의 영향관계를 규명하고자 한다. 본 연구를 위해 경상남도에 소재하는 항공 관

Received: September 3, 2021; $1^{\text {st }}$ Review Result: October 20, 2021; $2^{\text {nd }}$ Review Result: December 5, 2021 Accepted: January 29, 2022 
련 제조 기업에 근무하는 직원을 대상으로 설문지를 배포하였으며, 수집한 설문지 270부 중 불성실 답변 및 정화작업을 거처 분석에 사용된 설문지는 254부이다. 통계프로그램인 SPSS 21.0과 AMOS 21.0을 사용하여 분석하였다. 연구결과는 다음과 같다. 첫째, 안전규칙이 안전문 화디자인에 미치는 영향은 유의미한 긍정적 영향을 미치는 것으로 확인되었다. 둘째, 안전교 육이 안전문화디자인에 미치는 영향은 유의미한 긍정적 영향을 미치는 것으로 입증되었다. 셋 째, 위험처리방식이 안전문화디자인에 유의미한 긍정적인 영향을 미치는 것으로 확인되었다. 넷째, 안전문화디자인이 조직신뢰에 미치는 영향은 유의미한 긍정적 영향을 미치는 것으로 규 명되었다. 이러한 연구결과를 바탕으로 이론적, 실무적 시사점을 제시한다.

핵심어: 안전교육, 안전규칙, 안전의식디자인, 안전문화디자인, 조직신뢰

\section{1. 서론}

지속적으로 우리나라뿐만 아니라 세계에서도 많은 산업재해가 발생하고 있다. 최근 쿠팡 물류창고의 화재는 경제적 비용, 사회적 비용 및 인명사고 등을 초래하여 다시 한번 우리 사회에 안전의식디자인과 안전문화디자인에 대한 중요성을 일깨워 준다. OECD 국가의 산업재해율을 보면, 2017년 기준 우리나라의 사고사망자 수는 아이슬란드를 제외한 총 35 개국 중 상위 5 위이며, 특히 건설업은 상위 2 위를 차지하여 재해율이 현저히 높은 수준이다[1] .

우리나라의 산업재해율이 선진국에 비해 높은 것은 현재 환경의 변화에 의한 다양한 유해·위험요인 등으로 법규와 행정지도 감독 중심의 기존의 정책적 방법으로는 화재나 산업 현장의 사망사고 등의 산업재해를 감소시키는데에 한계를 보여주기 때문이다. 또한 안전관련 장비와 시설적인 측면에서 공학적 기술을 활용한 개선이 과거보다 많이 이루어지고 발전하였으나 안전문화디자인이 정착되지 못한 상태에서는 설비, 기기 등에 의한 공학적 방법과 기술만으로 안전경영을 담보하는 데는 어려움이 있다[2].

안전사고에 영향을 미치는 요인으로는 안전의식디자인, 안전장비설계디자인, 안전시스템디자인, 안전문화디자인 등이 있는데, 특히 기능적 측면에서의 안전디자인이 고려되고 있다. 우리 사회나 일반기업에서 안전사고가 수시로 발생하는 주요 요인은 무엇보다 안전의식이 성숙되지 않았거나 안전문화디자인의 정착이 이루어져 있지 않기 때문이다[3].

안전의 중요성이 강조되는 사회분위기 속에서 사고 발생을 줄이기 위해 최근 롯데그룹 계열사들은 $\mathrm{CEO}$ 의 지시로 각 계열사에 안전관리 조직을 대표이사 직속으로 격상하고, 안전관리시스템 및 매뉴얼 등을 고도화 하겠다는 계획을 발표하였다[4]. 많은 기업들이 자체적으로 안전경영을 위한 조직전담화 및 안전메뉴얼 고도화 등 새로운 정책들을 추진하고 있다. 해외의 우수한 안전문화디자인 활동으로는 미국의 자율안전 활동인 $\operatorname{VPP}($ Voluntary Protection Program)과 독일의 언론매체 및 스티커 등의 홍보물을 통한 적극적인 홍보활동 등이 있다. 이와 같은 다양한 안전경영 활동은 조직구성원의 안전의식디자인과 안전문화디자인을 향상시켜 안전사고를 감소시킬 수 있다.

선행연구들 중에는 안전문화디자인 인식이 심리적 조직유효성에 긍정적 영향을 미치며[5], 안전문화디자인은 개인의 안전의식디자인과 안전행동 및 조직의 성과에 긍정적 영향을 미친다[6]는 연구들이 있다. 하지만 안전의식디자인이 안전문화 디자인에 
미치는 영향에 관한 연구는 미흡한 편이라 이에 대한 규명이 필요하다. 또한, 안전의식디자인과 안전문화디자인의 영향 관계에서 최종적으로 구성원의 안전의식 디자인이 안전문화디자인을 통해 결과적으로 조직신뢰에 영향을 미치는 관계를 규명하고자 한다.

이에 본 논문에서는 안전사고의 주요한 영향요인인 안전의식디자인과 안전문화 디자인이 조직신뢰에 미치는 영향을 안전디자인 관점에서 조사 분석하여 시사점을 제시하고자 한다.

\section{2. 이론적 배경}

\section{1 안전규칙, 안전교육, 위험처리방식}

일반적으로 부적절한 사고와 부상은 개인의 안전의식 결여와 종업원, 관리자의 부적절한 행동으로부터 발생한다[7]. 이러한 안전의식디자인의 부족으로 인한 사고는 조직구성원의 안전교육 및 안전절차 준수 등의 철저한 관리가 이루어지지 않을 경우, 점차적으로 안전문화디자인을 약화시키게 된다. 이와 반대로 조직구성원의 안전준수 및 안전교육의 적극적 참여, 위험처리방식의 올바른 준수를 통한 작업장 분위기는 안전문화디자인을 구축하는데 도움을 준다. 일례로, 위국환 외(2021)[8]는 안전리더십, 안전준수, 안전교육, 안전문화디자인 간의 구조적 관계에 관한 연구에서 안전의식디자인의 하위요인인 안전준수, 안전교육이 안전문화디자인에 유의미한 긍정적인 영향을 미친다고 입증하였다. 그리고 이러한 연구결과를 통해 조직구성원의 안전준수, 안전교육의 중요성을 통한 안전문화디자인 창출을 강조하였다.

장미란, 김찬선(2017)[9]은 안전의식디자인의 하위요인을 안전교육, 안전규칙, 안전이해도, 위험처리방식으로 구분하여 안전문화디자인과의 인과 관계를 규명하였다. 그들은 안전교육, 안전규칙 및 위험처리방식이 안전문화디자인에 정적인 영향을 미친다고 보고하였다. 결과적으로 안전관리의식은 안전문화디자인에 영향을 미치고 이러한 안전문화디자인은 안전추구행동을 향상시키는 효과를 가져온다고 할 수 있다. Khan et al.(2018)[10]의 연구에서는 조직의 안전성과는 조직구성원의 안전의식 디자인과 안전문화디자인에 영향을 받는다고 하였다. 즉 조직의 안전성과는 조직구성원의 안전의식디자인 고취와 안전문화디자인의 성숙에 의해 가능한 것이다.

지금까지의 선행연구를 바탕으로, 안전규칙, 안전교육, 위험취급방식과 안전문화 디자인 간의 가설을 다음과 같이 설정하였다.

가설 1: 안전규칙은 안전문화디자인에 긍정적 영향을 미칠 것이다.

가설 2: 안전교육은 안전문화디자인에 긍정적 영향을 미칠 것이다.

가설 3: 위험취급방식은 안전문화디자인에 긍정적 영향을 미칠 것이다.

\section{2 안전문화디자인}

여러 연구에서 안전문화디자인을 조직문화의 하위 측면으로 설명했으며, 이는 일반적으로 조직이 운영의 안전 관련 측면을 관리하는 능력의 기본이 되는 중요한 개념으로 인식되고 있다[11]. 조직문화의 하위개념으로 안전문화디자인의 포괄적인 개념은 신념, 가치, 태도, 경험, 규범, 해석, 가정, 책임 인식, 행동 패턴, 작업장에서 일하는 모든 사람이 공유하는 건강과 안전을 향상시키기 위한 노력이며, 위험에 대한 
행동과 위험에 대한 예방조치를 형성하는 요소라고 하였다[12]. Clarke(2000)[13]는 안전문화디자인(Safety Culture Design)을 조직 속에 잠재하는 안전에 관한 기본 가치와 신념을 전제로 나타내는 것이라고 개념화하였다. 사실상, 체르노빌 사고 이후 안전문화디자인은 주요 대형사고의 원인으로 고려되고 있으며[14], 안전문화디자인과 조직의 성과는 다양한 산업 및 국가의 횡단면 연구에서 밀접한 연관성이 있음이 밝혀졌다[15]. 이와 같이 안전문화디자인은 조직의 관리에 있어서 매우 중요한 요소이다. 이재건(2016)[16]은 물류기업을 대상으로 안전의식디자인 수준이 조직신뢰와 조직몰입에 미치는 영향력 분석을 통해 조직구성원의 안전의식디자인은 조직신뢰를 가져온다고 주장하였다. 이를 바탕으로, 조직의 안전문화디자인은 조직구성원이 느끼는 조직신뢰에 유의미한 영향을 미칠 것으로 예측된다. 본 연구에서는 선행연구를 기본으로 아래와 같이 가설을 설정하였다.

가설 4: 안전문화디자인은 조직신뢰에 긍정적 영향을 미칠 것이다.

\section{3 조직신뢰}

조직신뢰란 조직이 유익하거나 해롭지 않을 것이라는 조직 구성원들의 전반적인 평가와 확신의 개념을 의미한다[17]. 조직에 대해 신뢰하는 조직구성원들은 조직신뢰를 통하여 조직구성원들에게 공동체의식을 가지게 됨으로써 보다 조직의 목표를 향해 자발적으로 참여하고 적극적인 태도와 행동을 보일 것으로 기대한다. 따라서 조직의 관리 및 운영에 있어서 조직 내에 안전교육수준의 향상, 안전한 작업환경을 갖출 시에 조직의 구성원들은 조직에 대한 신뢰도가 높을 것이여 이에 따라 업무에 자발적으로 참여하고 몰입하게 된다[16].

\section{3. 연구방법}

\section{1 연구모형}

본 논문은 안전의식디자인의 요소인 안전규칙, 안전교육, 위험처리방식, 안전문화디자인, 조직신뢰 간의 영향관계를 규명하고자한다. 따라서 안전의식디자인의 하위요인인 안전규칙, 안전교육, 위험처리방식이 안전문화디자인에 미치는 영향 및 안전문화디자인이 종속변수인 조직신뢰에 미치는 변수들 간의 관계에 대한 개념적인 연구모형은 [그림 1]과 같다.

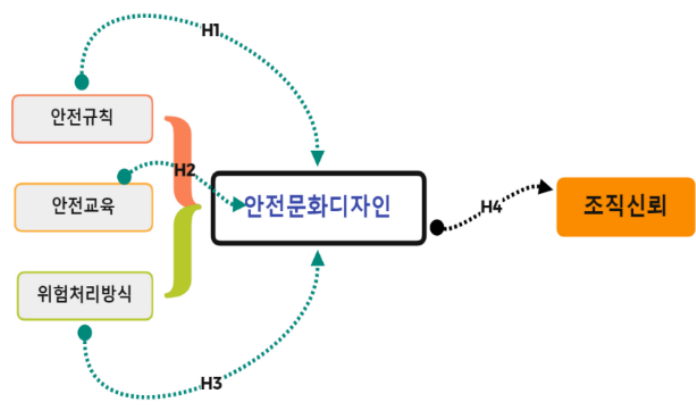

[그림 1] 연구모형

[Fig. 1] Research Model 


\section{2 조사설계}

\subsection{1 자료수집 및 분석방법}

본 연구의 목적을 달성하기 위해 경남에 소재하는 항공제조 기업에 근무하는 직원을 대상으로 설문지를 배포하였다. 설문은 2020년 2월 3일부터 2월 14일까지 실시하였으며, 수집한 설문지 270 부 중 불성실한 답변을 제거하고, 정화작업을 거쳐 최종 분석에 사용된 설문지는 254 부이다. 통계프로그램인 $\mathrm{AMOS} \mathrm{21.0을} \mathrm{사용해} \mathrm{신뢰성과} \mathrm{타당도}$ 검정을 위해 확인적요인분석과 상관관계분석을 적용하였고, 가설검정을 위해 경로분석을 실시하였다. 또한 안전의식디자인의 하위요소가 조직신뢰에 미치는 영향관계에서 안전문화디자인의 매개효과를 확인하였다.

\subsection{2 측정도구}

안전의식디자인에 대한 하위요인인 안전규칙(3문항), 안전교육(3문항), 위험처리방식 (3문항)에 대한 문항은 장미란과 김찬선(2017)[9]에 의해 사용된 문항을 보완수정하여 사용하였다. 안전규칙은 “나는 안전수칙을 잘 지키고 있다." 등 3 문항, 안전교육은 “나는 교육실시자의 안전교육 방법은 적정하다고 생각한다.” 등 3 문항, 위험처리방식은 “나는 작업현장에서 위험한 부분을 알았다면 안전조치를 취한 후 상급자에게 보고한다.” 등 3 문항으로 각각 구성하였다.

안전문화디자인 설문지는 장미란과 김찬선(2017)[9])에 의해 사용된 문항을 보완수정하여 “우리 회사는 급박한 상황일 때 규정과 절차를 따르지 않더라도 유연하게 안전조치를 취할 수 있다.” 등 3 문항으로 구성하여 사용하였다. 조직신뢰는 McAllister(1995)[18], 이재건(2016)[16]의 선행연구에 사용된 문항을 본 연구에 맞게 보완수정하여 “나는 전반적으로 회사를 믿고 따른다.” 등 3 문항으로 구성하여 사용하였다. 본 연구에 사용된 척도는 5단계 리커트(Likert) 척도로‘전혀 그렇지 않다(1점)’ ‘매우 그렇다(5점)'까지 측정하였다.

\section{4. 실증분석}

\section{1 확인적 요인분석}

본 연구에서 측정모형의 분석에는 $\mathrm{AMOS} \mathrm{21.0을} \mathrm{이용하였으며} \mathrm{최대우도법(maximum}$ likelihod)으로 적합도 지수를 통해 모형 평가를 실시하였다. 본 연구에서 확인적 요인분석을 사용하여 모형 적합도를 전반적으로 확인하기 위해 요인 적재치 등 기준에 미달되는 문항은 제외하였다. 제외한 각 문항의 요인 적재치가 0.6 이상으로 나타났으며, 각 변수의 Cronbach's $\alpha$ 값이 0.6이상, 개념신뢰도 값은 0.6 이상, 분산추출지수(AVE) 값은 0.5 에 근사한 값으로 나타났다. 측정모형을 구성하는 각 구성개념의 척도들은 수렴타당성과 집중타당성을 가진다고 볼 수 있다[19]. 적합도는 $\chi 2 / \mathrm{df}=86.770(788), \mathrm{p}=0.233$, $\mathrm{CMIN} / \mathrm{DF}=1.112, \mathrm{GFI}=0.957, \mathrm{IFI}=0.994, \mathrm{TLI}=0.992, \mathrm{CFI}=0.994, \mathrm{RMSEA}=0.087$ 로 나타나 전반적으로 적합한 것으로 판단된다. 또한, 각 변수의 Cronbach's $\alpha$ 값이 0.6 이상, 개념신뢰도 값은 0.6 이상, 분산추출지수(AVE) 값은 0.5 에 근사한 값으로 나타났다. [표 1]은 전체적인 신뢰도와 타당도를 분석한 결과이다. 
[표 1] 확인적요인분석 결과

[Table 1] Results of Confirmatory Factor Analysis

\begin{tabular}{|c|c|c|c|c|c|c|c|}
\hline Variables & Items & Estimates & SE & T-value & Cronbach' $\alpha$ & $\mathrm{CR}$ & AVE \\
\hline \multirow{3}{*}{$\begin{array}{l}\text { Safety } \\
\text { rules }\end{array}$} & $\mathrm{X} 1$ & 0.603 & 0.141 & $8.254 * * *$ & \multirow{3}{*}{0.713} & \multirow{3}{*}{0.924} & \multirow{3}{*}{0.464} \\
\hline & $\mathrm{X} 2$ & 0.727 & 0.149 & $8.418^{* * *}$ & & & \\
\hline & $\mathrm{X} 3$ & 0.703 & - & & & & \\
\hline \multirow{3}{*}{ Safety education } & $\mathrm{X} 4$ & 0.675 & 0.119 & $8.986^{* * *}$ & \multirow{3}{*}{0.717} & \multirow{3}{*}{0.719} & \multirow{3}{*}{0.460} \\
\hline & $\mathrm{X} 5$ & 0.683 & 0.108 & $9.049 * * *$ & & & \\
\hline & X6 & 0.677 & - & - & & & \\
\hline \multirow{3}{*}{$\begin{array}{l}\text { Danger handing } \\
\text { maner }\end{array}$} & $\mathrm{X} 7$ & 0.583 & 0.119 & $7.796^{* * *}$ & \multirow{3}{*}{0.664} & \multirow{3}{*}{0.677} & \multirow{3}{*}{0.411} \\
\hline & $\mathrm{X} 8$ & 0.643 & 0.113 & $7.463 * * *$ & & & \\
\hline & X9 & 0.693 & - & - & & & \\
\hline \multirow{3}{*}{$\begin{array}{l}\text { Safety culture } \\
\text { design }\end{array}$} & $\mathrm{X} 10$ & 0.758 & 0.094 & $12.177 * * *$ & \multirow{3}{*}{0.808} & \multirow{3}{*}{0.796} & \multirow{3}{*}{0.566} \\
\hline & $\mathrm{X} 11$ & 0.734 & 0.096 & $11.665^{* * *}$ & & & \\
\hline & $\mathrm{X} 12$ & 0.764 & - & - & & & \\
\hline \multirow{3}{*}{ Organizational trust } & X13 & 0.820 & - & - & \multirow{3}{*}{0.793} & \multirow{3}{*}{0.811} & \multirow{3}{*}{0.590} \\
\hline & $\mathrm{X} 14$ & 0.744 & 0.069 & $13.088 * * *$ & & & \\
\hline & $\mathrm{X} 15$ & 0.737 & 0.060 & $11.148 * * *$ & & & \\
\hline
\end{tabular}

$\chi 2 / \mathrm{df}=86.770(788), \mathrm{p}=0.233, \mathrm{CMIN} / \mathrm{DF}=1.112, \mathrm{GFI}=0.957, \mathrm{IFI}=0.994, \mathrm{TLI}=0.992, \mathrm{CFI}=0.994, \mathrm{RMSEA}=0.087$

Note: Significant value at $* * * \mathrm{p}=0.001$

\section{2 상관관계분석}

판별타당성 충족 수준을 검정하기 위해 잠재변인들 간의 상관관계와 분산추출 지수(AVE)의 크기를 비교하였다. 판별타당성을 검정한 결과, 잠재변인들 간의 제곱된 상관계수가 모두 $\mathrm{AVE}$ 값보다 낮게 나타났으며 판별타당성이 충분히 확보되었다[20]. 일례로 안전규칙의 $\mathrm{AVE}$ 제곱근 값인 0.681 은 안전규칙과 안전교육의 상관계수 값인 0.066 보다 크게 나타나 판별타당성이 확보되었다. 판별타당성 분석 및 상관관계 분석결과는 [표 2]와 같다.

[표 2] 판별타당성 분석 및 상관관계분석 결과

[Table 2] The Result of Discriminant Validity Analysis

\begin{tabular}{|c|c|c|c|c|c|}
\hline & V1 & $\mathrm{V} 2$ & V3 & V4 & V5 \\
\hline $\begin{array}{l}\text { Safety ruls } \\
\text { (V1) }\end{array}$ & 0.681 & & & & \\
\hline $\begin{array}{l}\text { Safety education } \\
\text { (V2) }\end{array}$ & 0.066 & 0.678 & & & \\
\hline Danger handing maner & 0.004 & -0.003 & 0.641 & & \\
\hline
\end{tabular}


(V3)

\begin{tabular}{|c|c|c|c|c|c|}
\hline $\begin{array}{l}\text { Safety culture design } \\
\text { (V4) }\end{array}$ & 0.072 & 0.037 & $0.242 * *$ & 0.752 & \\
\hline $\begin{array}{l}\text { Organizational trust } \\
\text { (V5) }\end{array}$ & 0.082 & 0.019 & -0.045 & $0.132^{*}$ & 0.768 \\
\hline
\end{tabular}

Note: Diagonal elements are each construct's AVE squared(in bold) Significant value at ${ }^{*} \mathrm{p}=0.01,{ }^{* *} \mathrm{p}=0.05$

\section{3 경로분석}

본 연구모형의 안전규칙, 안전교육, 위험처리방식, 안전문화디자인 간의 영향관계에 대한 가설검정을 위해 경로분석을 실시한 결과는 [표 3]과 같다. 경로모형의 적합도지수를 살펴본 결과 주요지표인 절대지표 값인 $\chi 2 / \mathrm{df}=167.752(77), \mathrm{CMIN} / \mathrm{DF}=2.179$, $\mathrm{GFI}=0.942$ 값이 모두 기준치를 충족하며, 또한 $\mathrm{RMSEA}=0.068$ 값도 0.8 이하로 양호한 것으로 나타났다. 증분적합지수 값도 $\mathrm{IFI}=0.943 \mathrm{TLI}=0.921, \mathrm{CFI}=0.942$ 로 각각 기준치를 충족하기 때문에 모형은 전반적으로 적합한 것으로 판단된다.

연구결과를 구체적으로 살펴보면 다음과 같다. 첫째, 안전규칙이 안전문화디자인에 미치는 영향에 대한 가설검정 결과 안전규칙이 안전문화디자인에 긍정적 영향을 미치는 것으로 확인되었다. 가설 1 은 경로계수 $=0.164, \mathrm{t}=2.423$ 으로 나타났으며 유의수준 $0.05 \%$ 에서 채택되었다. 둘째, 안전교육이 안전문화디자인에 미치는 영향에 대한 가설 검정 결과 안전교육이 안전문화디자인에 유의미한 긍정적 영향을 미치는 것으로 확인되었다. 가설 2 는 경로계수 $=0.603, \mathrm{t}=6.853$ 으로 나타나 유의수준 $0.001 \%$ 에서 채택되었다. 셋째, 위험처리방식이 안전문화디자인에 미치는 영향에 대한 검정결과 위험처리방식이 안전문화디자인에 유의미한 긍정적 영향을 미치는 것으로 확인되었다. 가설 3 은 경로계수 $=0.298, \mathrm{t}=3.767$ 로 나타나 유의수준 $0.001 \%$ 에서 채택되었다. 끝으로, 안전 문화디자인이 조직신뢰에 미치는 영향에 대한 검정결과 안전문화디자인은 조직신뢰에 긍정적 영향을 미치는 것으로 확인되었다. 가설 4 는 경로계수 $=1.031, \mathrm{t}=11.889$ 로 나타나 유의수준 $0.01 \%$ 에서 채택되었다.

[표 3] 경로분석 결과

[Table 3] Results of Path Analysis

\begin{tabular}{|c|c|c|c|c|c|c|}
\hline $\begin{array}{l}\text { Hypo- } \\
\text { thesis }\end{array}$ & Path & $\begin{array}{l}\text { Estim- } \\
\text { ates }\end{array}$ & SE & t-value & p-value & Results \\
\hline H1 & $\begin{array}{c}\text { Safety ruls } \\
\rightarrow \text { Safety culture design }\end{array}$ & 0.164 & 0.110 & $2.423 * *$ & $0.015^{* *}$ & 지지 \\
\hline $\mathrm{H} 2$ & $\begin{aligned} & \text { Safety education } \\
\rightarrow & \text { Safety culture design }\end{aligned}$ & 0.603 & 0.103 & $6.853^{* * *}$ & $* * *$ & 지지 \\
\hline $\mathrm{H} 3$ & $\begin{array}{l}\text { Danger handing maner } \\
\rightarrow \text { Safety culture design }\end{array}$ & 0.298 & 0.074 & $3.767 * * *$ & $* * *$ & 지지 \\
\hline $\mathrm{H} 4$ & $\begin{array}{l}\text { Safety culture design } \\
\rightarrow \text { Organizational trust }\end{array}$ & 1.031 & 0.097 & $11.889^{* * *}$ & $* * *$ & 지지 \\
\hline \multicolumn{7}{|c|}{ 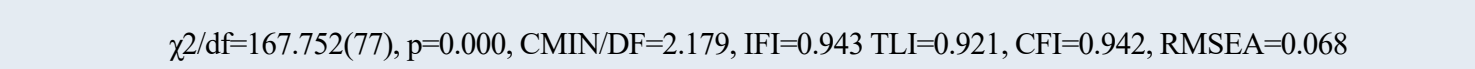 } \\
\hline
\end{tabular}

Note: Significant value at $* * \mathrm{p}=0.05, * * * \mathrm{p}=0.001$ 


\section{5. 결론}

안전문화디자인 요소를 포함하여 신뢰성이 높은 조직은 한 번에 설립되지 않는다. 높은 수준의 관심과 배려, 상사와 구성원 간의 신뢰 및 부서와 부서 간의 신뢰, 여러 정보 채널을 통한 풍부하고 투명한 의사소통를 통한 안전문화디자인을 유지 관리하는 것이 필요하다. 본 논문은 항공제조기업을 대상으로 구성원의 안전의식디자인, 안전문화디자인, 조직신뢰의 영향관계를 조사 분석하여 다음과 같은 연구결과를 도출하였기에 이에 따른 시사점을 제시하고자 한다.

첫째, 안전규칙이 안전문화디자인에 미치는 영향은 긍정적인 유의미한 영향을 미치는 것으로 확인되었다. 안전의식의 한 요인인 안전규칙 준수를 생활화하고 안전우선절차를 지키는 업무 프로세스는 조직의 안전문화디자인을 향상시킨다. 영국의 행동심리학자 헬렌무어(Hellen Muir)가 안전규칙의 사전숙지가 사고율을 감소시킬 수 있다고 강조한 바와 같이 안전규칙의 준수는 안전문화디자인 형성에 매우 중요한 요인이다. 따라서 조직구성원들의 안전규칙 준수가 조직의 안전문화디자인 구축을 위한 중요한 선행요인임을 인식하여 관리자는 물론 현장에서도 안전규칙 준수를 생활화하는 것이 중요하다.

둘째, 안전교육이 안전문화디자인에 미치는 영향은 유의미한 긍정적 영향을 미치는 것으로 입증되었다. 안전교육은 안전문화디자인을 향상시키는 영향요인이다. 안전교육을 통해 안전문화디자인이 정착되기 위해서는 실질적이면서도 효과적인 안전교육-안전사고 위험을 전제로 한 대응능력-내실 있는 안전교육이 중요하다. 안전교육을 실시하더라도 쉽게 안전문화디자인이 정착되는 것은 아니다. 안전교육이 현장에서 생활화되기 위해서는 지속적인 안전태도의 변화가 전제되어야 하므로 많은 시간이 요구된다[8]. 즉, 안전 교육은 일회성이 아닌 지속적인 교육을 바탕으로 안전태도와 행동의 변화를 통해 조직 내에 안전문화디자인이 정착될 수 있도록 해야한다. 또한, 안전교육이란 개인 자신뿐만이 아니라 함께 근무하는 동료의 생명까지도 존중하고 존엄성을 배우는 전인적인 교육으로서 개인, 팀, 부서, 조직으로 확대되어 조직의 안전문화디자인으로 정착되어야 한다.

셋째, 위험처리방식이 안전문화디자인에 미치는 영향은 긍정적인 유의미한 영향을 미치는 것으로 확인되었다. 하나의 사건에 대한 구성원의 위험처리 방식은 안전문화디자인 형성에 유의미한 영향을 미치는 선행요인이다. 따라서 규칙과 안전절차에 따라 위험요소를 처리하고, 위험 제어 메커니즘을 개선하는 더 나은 방법을 찾는 조직구성원의 태도나 행동은 안전문화디자인을 향상시킬 수 있다. 잠재적 위험 또는 노출된 위험에 대해 인식하고 처리하는 방법은 대형사고를 예방할 수 있는 중요한 요인이다.

넷째, 안전문화디자인이 조직신뢰에 미치는 영향은 유의미한 긍정적 영향을 미치는 것으로 규명되었다. 즉 안전문화디자인이 향상되면 조직 구성원들의 조직신뢰가 높아진다. 안전문화디자인이 성숙한 조직의 구성원들은 구성원들의 안전을 고려한 의사결정, 안전한 작업환경 조성 등을 통해 조직에 대한 신뢰를 갖게 된다. 신뢰는 조직의 위기에서 중요한 부분이며 이러한 조직에 대한 신뢰는 조직의 장기적인 안정을 가져오게 한다. 본 연구에서도 실증적으로 입증된 바와 같이, 조직의 안전은 현장의 근로자만이 아니라 감독자, 관리자 그리고 최고 경영자 모두가 조직의 가장 중요한 요소로 인식하고 받아들여 정책을 수립하고 실행할 때 우선순위가 되어야 한다. 이러한 
안전의식디자인이 모든 계층에 이루어질 때 안전문화디자인이 정착되어 조직의 신뢰가 높아지고 그러한 믿음은 바로 조직의 성과로 귀결된다.

다섯째, 추가적 제언으로 안전사고를 감소시키기 위해서는 $4 \mathrm{ED}$ 인 교육디자인 (Education Design), 제도디자인(Enforcement Design), 시설디자인(Engineering Design), 평가디자인(Evaluation Design)이 고려되어야 한다. 이러한 요소들 중 시설 및 장비의 디자인뿐만이 아니라 직무환경을 고려한 작업환경 디자인과 같은 요인도 안전사고를 사전에 줄이고 예방할 수 있는 중요한 요인으로 인식된다. 따라서 안전사고 감소의 요소인 시설, 장비 등의 설계에 있어서 미적인 부분보다는 안전를 고려한 디자인의 중요성에 무게를 둘 필요가 있다.

\section{References}

[1] S. Y. Choi, Comparison and analysis of fatal accidents in the construction industry in OECD countries, Construction \& Economy Research Institute of Korea, pp.1-95, (2020)

[2] S. K. Lee, C. B. Park, Y. S. Yoon, Research about Researcher's Safety Ethnic Level and Improvement Extent of Safety Culture, Based on Organizational Safety Efforts, Journal of the Korean Society of Safety, (2015), Vol.30, No.3, pp.123134, UCI: G704-000647.2015.30.3.003

[3] K. S. Song, B. J. Ahn, J. K. Rhim, The Effect of Safety Culture on the Safety Awareness and Safety Behavior of Manufacturing Workers, Journal of the Korean Society of Safety, (2019), Vol.34, No.6, pp.65-75, DOI: 10.14346/JKOSOS.2019.34.6.65

[4] https://news.zum.com/articles/69263681?cm=front_nb\&selectTab=total1\&r=5\&thumb=0, Jun $6(2021)$

[5] S. N. Hong, A Study on the Impact of Safety Culture Perceptions of Flight Attendants on the Psychological Organizational Effectiveness: Moderating Effect of Vocational Calling, Hotel Management, Graduate School of Kyunghee University, Ph.D dissertation, pp.1-171, (2020)

[6] M. Y. Kim, An Empirical Study on the Effects of Safety Culture for Safety Performance, Industrial and Management Engineering, Graduate School of Myongji University, Ph.D dissertation, pp.1-125, (2017)

[7] Y. M. Goh, C. U. Ubeynarayana, K. L. X. Wong, B. H. W. Guo, Factors influencing unsafe behaviors: A supervised learning approach, Accident Analysis \& Prevention, (2018), Vol.118, pp.77-85, DOI: 10.1016/j.aap.2018.06.002

[8] K. H. Wee, W. S. Bang, S. H. Kim, S. R. Chang, Structural Relations Between Safety Leadership, Safety Observance, Safety Education, and Safety Culture - K Company Case Study -, Journal of the Korean Society of Safety, (2021), Vol.36, No.1, pp.36-43.

[9] M. R. Jang, C. S. Kim, Relationship Between Safety Culture, Safety Behavior and Safety Management Awareness of Leisure Sports Player, Korean Journal of Convergence Science, (2017), Vol 6, No.3, pp.42-56.

[10] N. Khan, I. Ahmad, M. Ilyas, Impact of ethical leadership on organizational safety performance: the mediating role of safety culture and safety consciousness, Ethics \& Behavior, (2018), Vol.28, No.8, pp.628-643, DOI: $10.1080 / 10508422.2018 .1427097$

[11] A. I. Glendon, S. Clarke, E. McKenna, Human Safety and Risk Management. CRC Press, pp. 1-487, (2006)

[12] E. P. Fındıkçıoğlu, Investigation of Workplace Accidents in Coal and Mineral Processing Plants: Unsafe Acts, Safety Culture and Safety Leadership, Middle East Technical University, Ph.D dissertation, pp.1-175, (2018)

[13] S. Clarke, Safety culture: under-specified and overrated?, International Journal of Management Reviews, (2000), Vol.2, No.1, pp.65-90, DOI: 10.1111/1468-2370.00031

[14] J. Martyka, K. Lebecki, Safety culture in high-risk industries, International Journal of Ooccupational Safety and Ergonomics, (2014), Vol.20, No.4, pp.561-572, DOI: 10.1080/10803548.2014.11077076 
[15] K. J. Lee, G. S. Song, The Effect of Safety Culture on Job Satisfaction and Organizational Commitment - Mediation effect of Organizational Trust-, (2013), Vol.15, No.3, pp.71-81, DOI: 10.12812/ksms.2013.15.3.71

[16] J. G. Lee, An Empirical Study on the increasement of organizational. Trust and commitment using Effect of Safety Climate - Focused on Clothes Distribution Center, Graduate School of Myongji University, Ph.D dissertation, pp.1123, (2016)

[17] H. H. Tan, C. S. Tan, Toward the differentiation of trust in supervisor and trust in organization, Genetic, social, and general psychology monographs, (2000), Vol.126, No.2, pp.241-301.

[18] D. J. McAllister, Affect-and cognition-based trust as foundations for interpersonal cooperation in organizations, Academy of Management Journal, (1995), Vol.38, No.1, pp.24-59, DOI: 10.5465/256727

[19] D. Harrington, Confirmatory Factor Analysis, Oxford University Press, pp.1-121, (2009)

[20] C. F. Falk, J. C. Biesanz, Two cross-platform programs for inferences and interval estimation about indirect effects in mediational models, Sage Open, (2016), Vol.6, No.1, pp.1-13, DOI: 10.1177/2158244015625445 